\title{
Identifying the Factors Affecting Coordination among Different Agencies with ATMA in Andhra Pradesh, India
}

\author{
N. Hema Sarat Chandra ${ }^{\text {* }}$, K.S. Kadian ${ }^{2}$ and Rajiv Baliram Kale ${ }^{3}$ \\ ${ }^{1}$ Agricultural Extension, Dr.YSRHU, C.O.H. Anantharajupeta, Kadapa, \\ Andhra Pradesh, 516105, India \\ ${ }^{2}$ Dairy Extension Division, NDRI-Karnal, Haryana, India \\ ${ }^{3}$ Z.P.D, Zone VI, CAZRI Campus, Jodhpur, Rajasthan, India \\ *Corresponding author
}

\begin{abstract}
A B S T R A C T
The pluralistic extension service requires a central coordinating agency for its success. In India ATMA working at grass root level through bottom up approach and trying to coordinate different extension, research organizations with farming community. Information from several sources is extended, funds are effectively utilised and duplication

Keywords

Factor analysis, ATMA-KVK

convergence,

Coordination of

ATMA.

Article Info

Accepted:

10 September 2017

Available Online:

10 November 2017 of work is avoided for the agricultural development through ATMA. The complete procedure to measure the coordination of ATMA and the factors governing the coordination is described in this paper. The five categories of coordination as data analysed using cumulative square root frequency method (CSRF method). According to the data obtained and analysed, most of the respondents $(29.85075 \%)$ represents there is a high coordination followed by medium $(25.37313 \%)$ coordination and Low coordination $(16.41791 \%)$. However, few respondents were represented for Very high coordination $(13.43284 \%)$ as well as for Very low coordination $(14.92537 \%)$ of ATMA with different agencies at the level. Form pilot cum phase one of ATMA is showing a better coordination. Factor analysis used to identify seven factors effecting coordination viz. Roles and Responsibility of agencies, organizing ability of the ATMA, Combine plan and implementation, Degree of interest of agencies, Individuals' degree of contribution, Mutual trust in problem solving and Participation and efficiency of fund sharing among agencies. It helps extension functionaries to give emphasis on identified factors for effective performance. Further, suggests the policy makers to plan ATMA like programs still effective way.
\end{abstract}

\section{Introduction}

About a decade ago, in order to introduce reforms in the public sector agricultural extension system and increase its relevance, accessibility, and efficiency of knowledge sharing among various actors, players, and stakeholders, the Agricultural Technology Management Agency (ATMA) was introduced in India. It is one of the huge public extension systems of the world. ATMA Extension intervention is based on the Strategic Research and Extension Plan (SREP) prepared after a Participatory Rural Appraisal (PRA) in each district. SREP is a comprehensive document identifying research/ extension priorities for district, keeping in mind agro-ecological conditions 
and existing gaps in technology generation and dissemination in all agriculture and allied sector areas/ activities. SREP is prepared for the districts in coordination with the line departments, Krishi Vigyan Kendras (KVKs), Panchayati Raj Institutions (PRIs), Private Sector, farmers and other stake-holders at the district level. An institutional arrangement in the form of ATMA at the district level was created for coordinating the extension activities. The focus had been more on implementation of activities rather than systemic reforms viz. bottom up planning, multiagency extension strategy, gender mainstreaming, coverage of allied sectors \& convergence.

At the Block level, two bodies viz. Block Technology Team (BTT) (a team comprising officers of agriculture and all line departments within the block) and Block Farmers Advisory Committee (BFAC) (a group exclusively consisting of farmers of the block) shall continue to function jointly (with the latter providing farmers' feedback and input). BFACs shall represent Farmer Interest Groups (FIGs) / FOs existing within the block on rotation basis to advise the BTT. The Farmer Friend (FF) will serve as a vital link between extension system and farmers at village level (one for every two villages). The FF will mobilize farmers' groups and engage them in extension activities.

ATMA represents a platform for integrating extension programs across line departments, such as animal husbandry, fisheries, and forestry; linking research and extension units in a district; and inviting farmer participation in decision making (Swanson 2008).The guidelines for Support to State Extension Programmes for Extension Reforms' Scheme, 2010 report that ICAR should ensure that the research priorities of KVKs are in line with the SREPs, the KVKs should be an active partner to operationalize ATMA, and there should be no duplication between the activities of KVKs and extension activities of ATMA (Agarwal, 2005). However, the $11^{\text {th }}$ fiveyear plan highlighted that ICAR KVKs have very little interaction with ATMA, which functions under the Department of Agriculture and Cooperation (DAC) of the MoA (Planning Commission 2006). The ATMA structure has attempted to encourage greater linkages between extension services and the research institutions, with SAUs and KVKs now included in the organizational structure of ATMA.

In India much of the information on agriculture is generated in the institutes of the Indian Council for Agricultural Research (ICAR), which has a separate management structure, autonomous from the bureaucratic extension system managed through ATMA. The links between the two systems are known to be weak (Sulaiman and van den Ban, 2000). Although during NATP the two systems could be linked in some districts due to strong operational and financial support, this could not be sustained when scaled up to the whole country (Glendenning et al., 2011).

Swanson (2006) argued that decentralize public extension in India is difficult because the bureaucracy is highly entrenched: After decades of operating with a centralized, topdown, technology driven extension system, it is difficult to convince national and provincial- or state-level extension directors and senior managers to delegate decisionmaking authority to more junior-level staff members at the district and sub district levels (Swanson and Rajalahti, 2010 p53). Due to these critical arguments from different experiences of the researchers; it becomes pertinent to know the extent of coordination among different agencies with ATMA and the factors affecting coordination. Hence our present study conducted with the following objective. 
Objective of the study: To investigate the magnitude and the factors affecting coordination of ATMA for convergence of extension activities at district level.

\section{Materials and Methods}

Sampling: The study was conducted in Andhra Pradesh due to its exposure to ATMA since pilot stage i.e. 1998 under NATP and it has highest number (49 out of 302 in India) of Farmers' organizations (Small Farmers Agribusiness Consortium SFAC 2014). So this state has purposively selected for this study. ATMA has introduced in Andhra Pradesh state in three phases. One from each phase three districts have been randomly selected for this study. ATMAs are functioning as Block Technology Teams (BTTs) to cover all blocks (one BTT to each Block) in the district. All BTTs from three districts were considered for sampling. Each BTT is consisting of one Block Technology Manager (BTM) and two Assistant Technology Managers (ATMs) which are considered as the actual field extension functionaries in ATMA model. All block technology and assistant technology managers under selected three districts were considered as respondents. Persons from ATMA management committee including Project director, deputy project director and the officials of state department of agriculture \&allied sciences belonging to selected districts were also considered for study.

Instrument: ATMA coordination index (ACI) has developed for the purpose to measure the coordination under ATMA. ATMA makes coordination with different types of organizations includes state department of Agriculture and allied sectors, SAUs, KVKs, Research stations (ICAR, SAUs), private companies, NGOs, farmers' organizations etc. Hence three dimensions such as Coordination between ATMA and line departments,
Coordination between ATMA and KVKs, and Coordination between ATMA and farming community were made under ACI. Normalized rank order method (Guilford, 1954) was used to assign specific weights to each dimension based on their perceived significance by thirty judges. The items used to measure the coordination under ATMA (i.e. ACI) were developed based upon discussion with the extension professionals, KVKs, extension educators, extension scientists and from reviewed literature as well as authors own experience and knowledge on the criteria given by the Edwards (1957). These items sent for relevancy check in three point rating scale 'Most relevant', 'Relevant', 'Least relevant' with scoring 3, 2, 1, for positive statements and vice-versa for negative items. Finally fifty eight items were selected based on their Relevancy weight (RW) more than 0.75 and Mean Relevancy Score (MRS) more than 2.25.

Data Analysis: Interview schedule was prepared including all selected items and data was collected in a four point rating scale "Very true", "True", "Somewhat true", "Not true". The score 1 represented option "Not true" while score 4 represented the option "Very True". For data analysis all negative items were scored reverse. Thus, overall minimum and maximum scores of the respondents ranged from 119 and 199 respectively.

Each dimension of ACI consists of varied number of items hence their range of total scores was different. Therefore, the total score of each dimension was converted into unit score by using the following formula.

$U_{i j}=\frac{Y_{i j}-M i n Y_{i j}}{\operatorname{Max} Y_{j}-\operatorname{Min} Y_{j}}$

Where, 
$U_{i j}=$ Unit score of the $\mathrm{i}^{\text {th }}$ respondent on $\mathrm{J}^{\text {th }}$ dimension

$Y_{i j}=$ value of ith respondent on $\mathrm{J}^{\text {th }}$ dimension

$\operatorname{Max} Y_{j}=$ maximum score on the $\mathrm{J}^{\text {th }}$ dimension

$\operatorname{Min} Y_{j}=$ minimum score on the $\mathrm{J}^{\text {th }}$ dimension

Thus, the score of each dimension range from 0 to 1 i.e. when $Y_{i j}$ is minimum, the score is 0 and when the $Y_{i j}$ is maximum the score is 1 . Then the unit score of each respondent was multiplied by respective scale values of each dimension and summed up. Then the score obtained was divided by sum of scale values in order to get the index score values of each respondent.

$$
A C I_{i}=\frac{\sum U_{i j} \times S_{j}}{\text { Sum of scale values }}
$$

Where,

$A C I_{i}=$ ATMA coordination index score of $\mathrm{i}^{\text {th }}$ respondent.

$U_{i j}=$ Unit score of $i^{\text {th }}$ respondent on $\mathrm{J}^{\text {th }}$ dimension

$S_{j}=$ Scale value of the $\mathbf{J}^{\text {th }}$ component

\section{Results and Discussion}

The status of ATMA coordination was calculated based on the total index score of all indicators. With the help of cumulative square root frequency (CSRF) method respondents were classified into very low, low, medium, high and very high based on their index scores. Table 1 represents the five categories of coordination as data analysed using CSRF method. According to the data obtained and analysed, most of the respondents $(29.85075 \%)$ represents there is a high coordination followed by medium $(25.37313 \%)$ coordination and Low coordination (16.41791\%). However, few respondents were represented for Very high coordination (13.43284\%) as well as for Very low coordination (14.92537\%) of ATMA with different agencies at the level. The three districts representing the three phases of ATMA in the Andhra Pradesh state are having ACI scores as $0.62,0.70$, and 0.46 for East-Godavari, Chittore and Nellore districts. It clarifies the ATMA from Pilot cum Phase 1 (Chittore district) is maintaining good coordination with other agencies in the district in comparison to other phases so that it facilitates better convergence comparatively (Fig. 1).

It may due to the coordination is more of personal interest and responsibility of the functionaries, to understand the philosophy of synergism by all organizations certainly a time taking one and it includes experience the upshots.

\section{Factor analysis}

Factor analysis is a technique for identifying groups or clusters of variables towards any object (Field, 2005). The items were used for assessing factors affecting the coordination of ATMA with other agencies at district level related to one another for the $i^{\text {th }}$ respondent in a general form as follows

$$
Y_{e}=\sum_{f=1}^{n} a_{e, f} X_{f} ; \quad f=1,2, \ldots, n
$$

Where,

$Y_{e}$ : Coordination score of the $\mathrm{e}^{\text {th }}$ respondent

$a_{e, f}:$ Assessment of the $\mathrm{f}^{\text {th }}$ item by $\mathrm{e}^{\text {th }}$ respondent 
$X_{f}: \mathrm{f}^{\text {th }}$ item

$n:$ Number of items

Prior to performing factor analysis, test of sample adequacy was done through KaiserMeyer Olkin (KMO) test and Bartlett's test of sphericity. The KMO test is the measure of sampling adequacy ( 0.428 for this data), which varies between 0 and 1 .

If the KMO index value nearer to zero is, Principal component analysis won't be relevant. Further Bartlett's test of sphericity confirms the adequacy of the sample population by testing the null hypothesis that the variables in the population correlation matrix are uncorrelated and inadequate.

\section{Null Hypothesis (H0)}

There is no statistically significant interrelationship between factors affecting coordination of ATMA with other agencies at district level.

\section{Alternate Hypothesis (H1)}

There may be a statistically significant interrelationship between factors affecting coordination of ATMA with other agencies at district level.

Table.1 Coordination of ATMA with different agencies represented by the respondents by CSRF method $(\mathrm{n}=67 ; 4$ - point rating scale; $\mathrm{ACI}$ index score $(0$ to 1$)=0.604884$

\begin{tabular}{|c|c|c|c|c|}
\hline S.No & FIVE CATEGORIES & RANGE & Frequency & Percentage (\%) \\
\hline 1 & VERY LOW & till 0.462253 & 10 & 14.92537 \\
\hline 2 & LOW & $0.462254-0.566817$ & 11 & 16.41791 \\
\hline 3 & MEDIUM & $0.566818-0.643067$ & 17 & 25.37313 \\
\hline 4 & HIGH & $0.643068-0.714737$ & 20 & 29.85075 \\
\hline 5 & VERY HIGH & from 0.714738 & 9 & 13.43284 \\
\hline
\end{tabular}

Mean $=0.604884 ; \mathrm{SD}=0.113394$

Chandra (2016)

Table.2 Extractable factors along with their eigenvalues, the percent of variance

\begin{tabular}{|l|r|r|r|r|r|r|}
\hline \multicolumn{7}{|c|}{ Total Variance Explained } \\
\hline Component & \multicolumn{3}{|c|}{ Initial Eigenvalues } & \multicolumn{2}{c|}{ Rotation Sums of Squared Loadings } \\
\cline { 2 - 7 } & Total & \% of Variance & Cumulative \% & Total & \% of Variance & Cumulative \% \\
\hline 1 & 7.142 & 22.318 & 22.318 & 4.481 & 14.004 & 14.004 \\
\hline 2 & 4.627 & 14.460 & 36.778 & 4.133 & 12.916 & 26.920 \\
\hline 3 & 2.842 & 8.882 & 45.659 & 2.972 & 9.288 & 36.208 \\
\hline 4 & 2.144 & 6.701 & 52.360 & 2.753 & 8.602 & 44.810 \\
\hline 5 & 1.821 & 5.691 & 58.051 & 2.711 & 8.472 & 53.282 \\
\hline 6 & 1.638 & 5.119 & 63.170 & 2.498 & 7.808 & 61.090 \\
\hline 7 & 1.596 & 4.987 & 68.157 & 2.261 & 7.067 & 68.157 \\
\hline
\end{tabular}

Extraction Method: Principal Component Analysis. 
Table.3 Extracted factors along with their factor loadings

\begin{tabular}{|c|c|c|c|c|c|c|c|}
\hline \multicolumn{8}{|c|}{ Rotated Component Matrix } \\
\hline \multirow{2}{*}{\begin{tabular}{|} 
Variables \\
(code)
\end{tabular}} & \multicolumn{7}{|c|}{ Component } \\
\hline & 1 & 2 & 3 & 4 & 5 & 6 & 7 \\
\hline DD & .763 & & & & & & \\
\hline EE & .722 & & & & & & \\
\hline $\mathrm{Z}$ & .685 & & & & & & \\
\hline A & .670 & & & & & & \\
\hline $\mathrm{CC}$ & .611 & & & & & & \\
\hline $\mathrm{FF}$ & .587 & & & & & & \\
\hline Q & .493 & & & & & & \\
\hline $\mathrm{J}$ & .482 & & & & & & \\
\hline $\mathrm{D}$ & .469 & & & & & & \\
\hline $\mathrm{G}$ & & .899 & & & & & \\
\hline $\mathrm{C}$ & & .783 & & & & & \\
\hline $\mathrm{H}$ & & .697 & & & & & \\
\hline $\mathrm{Y}$ & & .601 & & & & & \\
\hline $\mathrm{X}$ & & .485 & & & & & \\
\hline $\mathrm{K}$ & & & .716 & & & & \\
\hline $\mathrm{L}$ & & & .636 & & & & \\
\hline $\mathrm{N}$ & & & .606 & & & & \\
\hline $\mathrm{E}$ & & & .605 & & & & \\
\hline $\mathrm{F}$ & & & .602 & & & & \\
\hline $\mathrm{U}$ & & & .486 & & & & \\
\hline $\mathrm{V}$ & & & & .771 & & & \\
\hline $\mathrm{I}$ & & & & .762 & & & \\
\hline $\mathrm{P}$ & & & & .570 & & & \\
\hline$S$ & & & & & .805 & & \\
\hline $\mathrm{R}$ & & & & & .761 & & \\
\hline $\mathrm{AA}$ & & & & & .511 & & \\
\hline \multicolumn{8}{|l|}{$\mathrm{O}$} \\
\hline M & & & & & & 620 & \\
\hline $\mathrm{BB}$ & & & & & & .427 & \\
\hline B & & & & & & & .677 \\
\hline $\mathrm{T}$ & & & & & & & .596 \\
\hline $\mathrm{W}$ & & & & & & & .591 \\
\hline \multicolumn{7}{|c|}{ Extraction Method: Principal Component Analysis. } & \\
\hline
\end{tabular}


Table.4 Factors obtained from factor analysis affecting coordination

\begin{tabular}{|c|c|c|}
\hline S.No & Factors affecting Coordination & Underlying Variables With respective Codes \\
\hline 1 & Roles and Responsibility of agencies & $\begin{array}{l}\text { (DD) Maintaining own web portal to share } \\
\text { information } \\
\text { (EE) Coordination more of personal interest } \\
\text { (Z) Convergence of other schemes } \\
\text { (A) Good understanding between agencies } \\
\text { delivering extension } \\
\text { (CC) Belief in coordination benefits agencies \& } \\
\text { farmers } \\
\text { (FF) ATMA works with NGOs \&PVT agencies } \\
\text { (Q) Increased service area } \\
\text { (J) Professional values } \\
\text { (D) Agencies do exchange information on } \\
\text { clients }\end{array}$ \\
\hline 2 & Organizing ability of ATMA & $\begin{array}{l}\text { (G) Number of organizations } \\
\text { (C) ATMA creates awareness on common } \\
\text { goals } \\
\text { (H) Synchronizing similar works } \\
\text { (Y) All agencies given importance } \\
\text { (X) SREP \& SWEP of ATMA are the tools for } \\
\text { coordination }\end{array}$ \\
\hline 3 & $\begin{array}{l}\text { Combined plan \& implementation of } \\
\text { Extension programs }\end{array}$ & $\begin{array}{l}\text { (K) Improved performance of agencies } \\
\text { (L) Reduced uncertainty } \\
\text { (N) Clear cut division of work } \\
\text { (E) Agencies plan well with ATMA } \\
\text { (F) Agencies implement well with ATMA } \\
\text { (U) Participation of agencies during the } \\
\text { programs of ATMA }\end{array}$ \\
\hline 4 & Degree of interest of agencies & $\begin{array}{l}\text { (V) Interest shown by the agencies } \\
\text { (I) Independency in coordination } \\
\text { (P) Degree of responsibility of agencies }\end{array}$ \\
\hline 5 & Individuals' degree of contribution & $\begin{array}{l}\text { (S) Strength of manpower } \\
\text { (R) Staff transfers } \\
\text { (AA) Duplication of work }\end{array}$ \\
\hline 6 & Mutual trust in problem solving & $\begin{array}{l}\text { (O) joint selection of beneficiaries } \\
\text { (M) combined problem solving } \\
\text { (BB) Mutual trust among agencies }\end{array}$ \\
\hline 7 & $\begin{array}{l}\text { Participation and efficiency of fund } \\
\text { sharing among agencies }\end{array}$ & $\begin{array}{l}\text { (B) Effective sharing of funds } \\
\text { (T) Participation of agencies during SREP } \\
\text { (W) Time management in coordination }\end{array}$ \\
\hline
\end{tabular}


Fig.1 Coordination of ATMA with other agencies in Andhra Pradesh, India

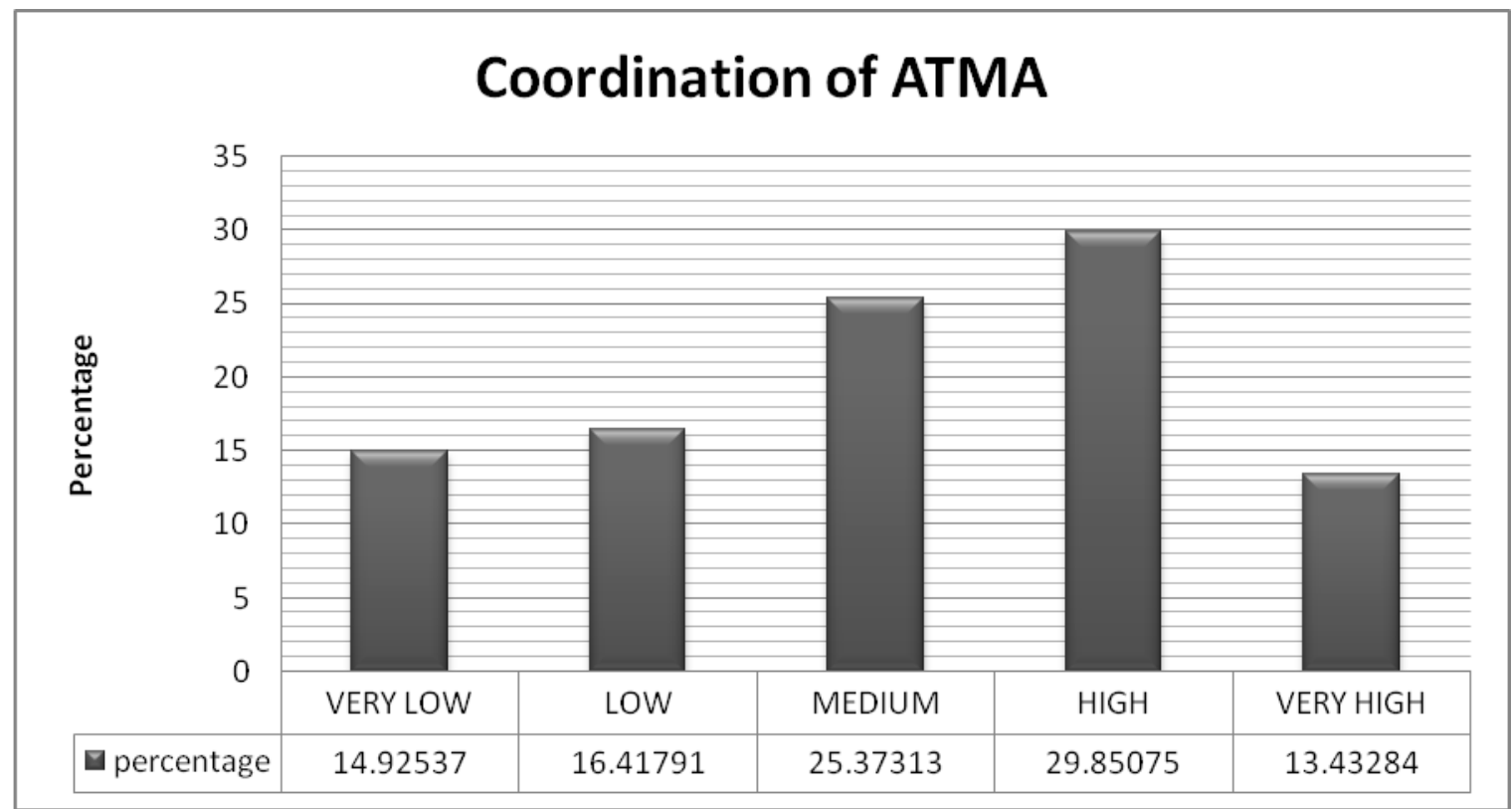

Fig.2 Magnitude of coordination by ATMA in three phases

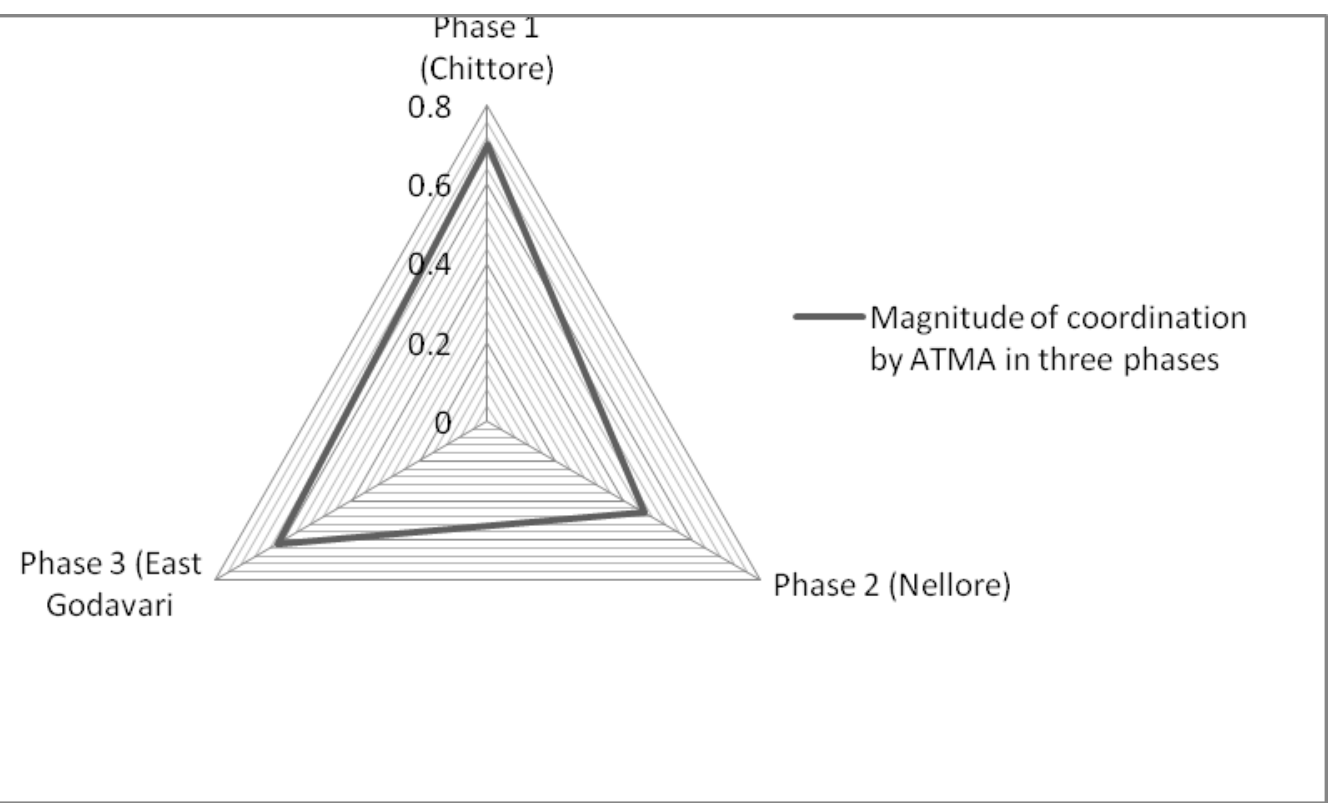

The Bartlett's test of sphericity had the pvalue (Sig.) of $0.000<0.01$, which indicated that the sample population was adequate so the null hypothesis was rejected and accepted the alternate hypothesis $(\mathrm{H} 1)$ that there may be statistically significant interrelationship between factors. The KMO and Bartlett's test measure of sampling adequacy was used to examine the appropriateness of Factor Analysis. The approximate of Chi-square was 1629.280 with 496 degrees of freedom, which is significant at $1 \%$ level of significance. 
Thus, the data was suitable and supports the factorability of the correlation matrix.

The eigenvalues $\geq 1$ were considered for the number of components to be generated. The eigenvalues associated with each component represent the variance explained by that particular linear component (Field, 2005). Table 2 shows all the factors extractable from the analysis along with their eigenvalues, the percent of variance attributable to each factor, and the cumulative variance of the factor and the previous factors. The eigenvalues of the first seven components from the principal component analysis were larger than 1 i.e. 7.142, 4.627, 2.842, 2.144, 1.812, 1.638 and 1.596 respectively.

The variance has explained by these seven components were 22.318, 14.460, 8.882, 6.701, 5.691, 5.119 and 4.987 per cent respectively. All the remaining components were not significant. The first component accounted for the highest variance (and hence had the highest eigenvalue) and the next component accounted for as much of the left over variance as it could, and so on. Thus, these seven components accounted for 68.157 per cent of variance which is regarded as satisfactory in social sciences (Hair Jr. et al., 2006).

\section{The extracted factor loading by Varimax rotation}

In order to obtain a meaningful representation of items and factor mapping along the principal axis, the resulted principal component was rotated using orthogonal transformation by varimax. The items with loadings equal to or greater than 0.4 were considered meaningful and extracted for factor analysis (Field, 2005). Table 3 reveals how the item analysis reduced original fifty eight items into seven independent components (factors). The results show that the factor loadings ranging from 0.763 to 0.469 were substantially loaded on the component 1 subscale, from 0.899 to 0.485 on the component 2 subscale, from 0.716 to 0.486 on the component 3 subscale, from 0.771 to 0.570 on the component 4 , from 0.805 to 0.511 on the component 5 , from 0.822 to 0.427 on component 6 and from 0.677 to 0.591 on the component 7 subscale.

The behaviour of individual items in relation to others within the same subscale provides good evidence for content validity because the highest factor loading is central to the domains assessed by these subscales (Francis et al., 2000).

These seven factors were named based on the variables included in respective components (factors). The seven components (factors) along with their underlying variables were shown in Table 4.

ATMA is a huge public extension system of India. So far 614 ATMAs are there in all Indian states. It acts as a major coordinating body to converge several extension works at district level, it facilitate demand driven extension and research in agriculture. It successfully coordinates research agencies, private agencies, NGOs with farming community. In this paper an attempt has made to measure the magnitude of coordination provided by ATMA with other agencies in Andhra Pradesh state using ACI (developed by author) and identified factors governing this coordination (Fig. 2). Identified seven factors viz. Roles and Responsibility of agencies, organizing ability of the ATMA, Combine plan and implementation, Degree of interest of agencies, Individuals' degree of contribution, Mutual trust in problem solving and Participation and efficiency of fund sharing among agencies. It helps extension functionaries to give emphasis on identified factors for effective performance. Further, 
suggests the policy makers to plan ATMA like programs still effective way.

\section{Acknowledgement}

The author acknowledges the University Grant Commission (UGC), Government of India for financial support to carry out research work.

\section{References}

Agarwal, A. K. 2005. Joint secretary letter. D.O. No. 27(1)/2003-NATP (TC)SEWP/AE. New Delhi: Department of Agriculture and Cooperation. <http://www.manage.gov.in/ExRef/jslet ter.htm>. Accessed July 25, 2014.

Chandra, N.H.S. 2016. Dynamics of coordination among different agencies with ATMA in Andhra Pradesh. Ph.D. thesis; National Dairy Research Institute (NDRI), Karnal, India.

Edwards, A. L. 1957. Techniques of attitude scale construction. Vakils, Feffer and Simons Private Ltd. Ballard Estate, Mumbai.

Field, P. 2005. Discovering statistics using SPSS for Windows: Advanced techniques for the beginner. Sage, London, UK.

Francis, L., Katz, Y. \& Jones, S. 2000. The reliability and validity of the Hebrew version of the Computer Attitude Scale. Computers \& Education, 35 (2), 149159.

Glendenning, c. j. and Babu, S.C. 2011. Decentralization of Public-Sector
Agricultural Extension in India Case of the District-level Agricultural Technology Management Agency (ATMA). IFPRI Discussion Paper 01067. Washington, D.C.: International Food Policy Research Institute.

Guilford, J.P. 1954. Psychometric methods ( $2^{\text {nd }}$ ed.). McGraw-Hill, the University of Wisconsin - Madison, New York.

Hair Jr., J. F., Black, W. C., Babin, B. J., Anderson, R. E. \& Tatham, R. L. 2006. Multivariate Data Analysis, 6th Edition. Pearson Education, Inc., Upper Saddle River, New Jersey.

Planning Commission. 2006. Towards faster and more inclusive growth: An approach to the 11th five year plan (2007-2012).New Delhi.

SFAC. 2014. State Wise Details of Farmer Producer Organizations (FPOs) - as on 10th March 2014. Available at: http://sfacindia.com/PDFs/StatewiseList-of-FPOs2014.pdf

Sulaiman, R. V., and A. W. van den Ban. 2000. Agricultural extension in Indiathe next step. New Delhi: Indian Centre for Agricultural Research.

Swanson, B. (2008) Global review of good agricultural extension and advisory service practices. Rome: United Nations Food and Agriculture Organisation.

Swanson, B. and R. Rajalahti. 2010. Strengthening Agricultural Extension and Advisory Systems: Procedures for Assessing, Transforming, and Evaluating Extension Systems, Agricultural and Rural Development Discussion Paper 45.World Bank.

\section{How to cite this article:}

Hema Sarat Chandra, N., K.S. Kadian and Rajiv Baliram Kale. 2017. Identifying the Factors Affecting Coordination among Different Agencies with ATMA in Andhra Pradesh, India. Int.J.Curr.Microbiol.App.Sci. 6(11): 890-899. doi: https://doi.org/10.20546/ijcmas.2017.611.104 